\title{
Influence of family socioeconomic status on IQ, language, memory and executive functions of Brazilian children
}

\author{
Luciane da Rosa Piccolo*, Adriane Xavier Arteche, Rochele Paz Fonseca, Rodrigo Grassi-Oliveira \\ and Jerusa Fumagalli Salles
}

\begin{abstract}
The aim of this study was to assess the effect of family socioeconomic status (SES) and parental education on non-verbal IQ and on the processing of oral and written language, working memory, verbal memory and executive functions in children from different age ranges. A total of 419 Brazilian children aged 6-12 years old, attending public and private schools from Porto Alegre, RS participated in the study. Structural equation analyzes revealed that in the general model (for all ages), the SES contributed to cognitive performance - IQ, verbal memory, working memory, oral and written language and executive functions $(28,19,36,28$ and $25 \%$, respectively). SES had stronger effects on younger children (up to nine years old), in most cognitive tasks examined. Probably, after this age, a combination of factors such as schooling, living in other social environments, among others, may mitigate the effects of family socioeconomic status.
\end{abstract}

Keywords: Neuropsychological assessment, Language, Memory, Executive functions, Socioeconomic status

\section{Background}

Socioeconomic status (SES) refers to an individual's place in society and strongly influences the individual experience since childhood and during adult life (Hackman et al. 2010; Lipina and Segretin 2015). It is usually assessed through indicators such as education, occupation and family income or a combination thereof (Braveman et al. 2005). In studies in childhood and adolescence, SES is often measured by family income and parental education (ABEP 2009).

Research in animals and humans show that early malnutrition, stress, lack of stimulation and poor social interaction can affect the structure and functioning of the brain, with long lasting cognitive and emotional effects (Hackman et al. 2010; Noble et al. 2015). Despite the large number of studies on psychosocial factors and their impacts on the performance of children of different ages in cognitive tasks, most of them use IQ or academic achievement measures (Forns et al. 2012; Haan et al. 2011). In the present study, neuropsychological variables were added to traditional IQ evaluation, following recent

\footnotetext{
* Correspondence: lucianepiccolo@gmail.com

Universidade Federal do Rio Grande do Sul, Porto Alegre, RS, Brazil
}

studies that assess neuropsychological functions separately (Noble and Farah 2013; Raizada and Kishiyama 2010).

Family SES, especially during early childhood, seem to affect performance in some neuropsychological systems more than in others, particularly memory (episodic, working and semantic), oral and written language and executive functions (Hackman et al. 2010; Piccolo et al. 2014) - in this study, we will investigate that cognitive functions. Such influence is more prominent at younger ages (Tomalski et al. 2013), until about ten years old (Lupien et al. 2001), probably due to their complexity and prolonged development (Evans and Fuller-Rowell 2013; Noble et al. 2006, 2007). In the first years of childhood, the socioeconomic status is very important for children development, since it may limit the conditions for stimulation, access to materials and activities that favor cognitive development (Forns et al. 2012).

About that neuropsychological functions development, the neural structures necessary for language processing are available in children from an early age and this skill is developed and strengthened from the experiences, social relations and communication interactions and is therefore a complex process (Finkbeiner and Coltheart 2009). The 
acquisition of written language (literacy) occurs later in childhood, being an ongoing task, which is enriched with new skills as the individual develops and interacts with the environment. In this sense, environmental aspects, both social and economic - as material resources -, and psychosocial - like mental health of parents and family relations - have been linked to academic performance and the development of language (Marturano 2006; Noble et al. 2006).

The executive functions have been defined as a set of skills that in an integrate manner, enable the individual to direct behaviors to goals, performing voluntary actions. Such actions are self-organized, by evaluating their suitability and efficiency to the intended purpose, in order to elect the most efficient strategies, solving thus immediate and/or medium to long term problems (Banich 2009; Fuster 2002). According to Diamond (2013), the core executive functions are inhibition - response inhibition and interference control -, working memory and cognitive flexibility (Diamond 2013). As Weyandt (2005) highlights, these definitions differ to the degree of emphasis placed either in process control, working memory, inhibition, or other components. There is a progressive development of inhibitory function and the prefrontal areas of the brain. Thus, younger children are less efficient in inhibiting behavior than older children that will improve this ability with age (Brocki and Bohlin 2004).

Although working memory can be considered as a subcomponent of executive functions (Blair et al. 2005; Diamond 2013) in this study we evaluated separately inhibitory control as a component of executive functions and investigated phonological loop, visuospatial sketchpad and central executive, the three of the four components of Baddeley's working memory model (Baddeley 2000). In its classic formulation, working memory consists of separate storage buffers for verbal and visuospatial content, as well as executive processes that act upon the information in the storage buffers (Baddeley 2000).

Besides the study of the influence of a socioeconomic index on the development of those cognitive functions, some authors have studied specific influences of family variables, such as parental education. The educational level of parents, especially the mother (Cesare et al. 2013; Villaseñor et al. 2009), is associated with a higher cognitive performance, which was observed in North American (Noble et al. 2006, 2007), Finnish (Klenberg et al. 2001), British (Cesare et al. 2013) and Latin-American (Ardila et al. 2005) families. As Carneiro et al. (2013) affirm, part of the effects that are attributed to mother's education may be driven by the father's schooling through an overlapping effect. However, unless the effect of partner's schooling is incredibly large, this overlapping effect cannot fully explain their results. Those authors find, for example, that an additional year of mother's schooling increases the child's performance on a standardized math test by almost 0.1 of a standard deviation and that effect was observed also in reading at ages $7-8$. It seems that more educated mothers are more likely to have better educated husbands, higher income, they are more likely to invest in books, special lessons and materials (like computers) for their children and those things could explain the maternal education impact in children cognitive development (Carneiro et al. 2013). In this study, one of the research questions is to investigate the specific role of parental education, as a separate variable of the SES, asking which SES variables actually impact in neuropsychological development.

Although it has been demonstrated that better environmental conditions are associated with better performance in neuropsychological tasks (Evans and Fuller-Rowell 2013; Noble and Farah 2013), some studies found no differences associated to the socioeconomic status in the performance of executive functions (inhibitory control) (Wiebe et al. 2008), working memory and oral and written language (Engel et al. 2008; Waber et al. 2007). This lack of effect can be partly explained by sample performance homogeneity (Wiebe et al. 2008) or strict exclusion criteria (Waber et al. 2007), resulting in samples of healthy children with high IQ in spite of their unfavorable SES (Hackman et al. 2010). In Engel et al. (2008) study, for example, groups were matched on nonverbal IQ which might have washed out differences in other related cognitive systems (e.g. working memory).

In Latin-American samples (Mexico, Argentina, Brazil), authors have found associations between parental education and the performance of children and adolescents (aged 3-13 years) in tasks of attention and verbal and visual memory (Villaseñor et al. 2009), executive functions (Ardila et al. 2005; Arán-Filippetti 2011; Lipina et al. 2013) and written language (Cuadro and Balbi 2012). Brazilian studies that not found effects of SES on cognition (Lúcio et al. 2010; Miranda et al. 2007) or show relations in the opposite directions (Lúcio et al. 2010) attribute these results to the sample characteristics or good quality of the schools (Lúcio et al. 2010) and recognize that no other studies resembled they results. Miranda et al. (2007) explained their uncommon results due to the use of inadequate variables to measure the constructs of interest. They wanted to study the quality of the home environment, but substitute that for "poverty measures" that were done indirectly, by the variable "free or reduced-price lunch program and charter school". So, it seems the results from those Brazilian studies run into methodological obstacles that have produced biases in their research and hindered the analysis of their data.

In short, family SES in childhood seems to affect the general cognitive performance (IQ) but some neuropsychological systems more than in others, particularly 
memory (episodic, working and semantic), oral and written language and executive functions (Hackman et al. 2010). Starting from the importance of empirically investigate this issue and provide evidence to support prevention and intervention programs in child development, the aim of this study was to compare the effect of family SES (and specifically parental education) between age ranges regarding IQ performance, language (oral and written), memory (episodic, semantic and working) and executive functions (inhibitory components and cognitive flexibility, in particular) in children from 6 to 12 years old. The hypothesis was that the relationship between low socioeconomic status (including low parental education) and lower performance in IQ and in the assessed tasks (Ardila et al. 2005; Noble et al. 2007) would be more noticeable in younger children (Blair et al. 2011; Lupien et al. 2001). This study intends to give a better comprehension about this issue in Brazil, providing evidences from a large sample, using classical measures of SES and neuropsychological tasks based on traditional paradigms (besides IQ measures), with robust statistical analysis, that could be the basis for rethinking public policies that promote child development.

\section{Method}

\section{Design}

This is a quantitative, descriptive-explanatory study. The dependent variables are IQ and performance in tasks that assess language, verbal memory, working memory and executive functions. The independent variables are children age, parental education and family socioeconomic status according to a survey of the Brazilian Association of Research Companies - ABEP (2009), an index (combining parental education and income) that characterizes the family socioeconomic status.

\section{Participants}

A total of 419 Brazilian children selected by convenience sampling, $54.4 \%$ females, aged $6-12$ years old $(M=9.08$; $S D=1.93$ ), 213 attending public (3 schools with basic education development index - IDEB $=4,3$ each) and 206 private (2) schools (from 1st to 7th grade) in Porto Alegre, Rio Grande do Sul, participated in the study. The children, without grade repetition, monolinguals (basic English classes in their schools) and native speakers of Brazilian Portuguese, with no history of neurological or psychiatric illnesses, uncorrected auditory and visual impairments, according to a questionnaire completed by the parents, belonged to families of SES A (30.2\%), B1 and B2 (51\%), $\mathrm{C}(18.6 \%)$ and D $(0.2 \%)$, according to the ABEP's classification (A is the highest level and $\mathrm{E}$ is the lowest). On the other hand, $56 \%$ of the Brazilian families belong to SES C (IBGE 2012). No performance differences were found on the cognitive tasks evaluated in this study in children aged 6-7 years old, 8-9 years old and 10, 11 and 12 years old. We then decided to split the sample in these three age ranges.

The exclusion criteria were: performance below the 25th percentile at Raven's Colored Progressive Matrices test - Special Raven's Scale (Angelini et al. 1999) and/or indicators of behavioral changes and Attention deficit hyperactivity disorder (ADHD), assessed using Conners Abbreviated Teacher Rating Scale - CATRS-10)(Brito 1987). According to a study of Brito (1987), the cutoff point suggested for the Brazilian population is a performance above the $90^{\text {th }}$ percentile. We only evaluate children who fit the inclusion criteria. No child was excluded after cognitive assessment.

\section{General procedures}

This study was approved by the Ethics Committee of the Institute of Psychology of Universidade Federal do Rio Grande do Sul (UFRGS), under protocol 2008/067. The children were assessed only after their parents or guardians signed the Informed Consent Form (TCLE). The schools were selected by convenience sampling and the names of the students from each grade were randomly selected (draw). The children were assessed in two sessions, one collective session (Raven's Colored Progressive Matrices test - Special Raven's Scale, Angelini et al. 1999), lasting approximately $20 \mathrm{~min}$, and one individual session of approximately $60 \mathrm{~min}$ (neuropsychological tasks).

\section{Specific instruments and procedures}

Non-verbal intelligence was assessed by Raven's Colored Progressive Matrices test - Special Raven's Scale (Angelini et al. 1999).

Subtests of verbal memory, working memory, oral and written language and executive functions of the Child Brief Neuropsychological Assessment Battery NEUPSILIN-INF(de Salles et al. 2011, in press). The following memory tasks were used for this study: digit span (forward and backward) (maximum score: 28 points), pseudoword span (maximum score: 20 points), visuospatial working memory (similar to Corsi Blocks, but on 2 D, maximum score: 28 points), immediate recall of a list of (nine) words, immediate recall of (nine) figures showed to children (visuoverbal episodic memory) and semantic memory (4 general knowledge questions -1 point each). For assessment of language: rhyme task (children had to say which words rhyme, total score of 4 points), phonemic subtraction (take off one phoneme of a composite threeletter syllable, total score of 6 points), listening comprehension (5 points), inferential processing (total score of 8 points), reading aloud (17 points), reading comprehension (total score of 5 points), spelling (total score of 19 points), spontaneous writing and written 
copies of words. The following tasks were used for assessment of executive functions: orthographic verbal fluency, semantic verbal fluency and auditory go-nogo (children heard a sequence of numbers and had to say "yes" to every number but 8 , when they supposed to stay quiet).

\section{Results}

Table 1 includes the participants' performances (mean and standard deviation) in IQ (Raven) and in memory, language and executive functions of the NEUPSILIN-INF, by socioeconomic status and age range.

In order to assess the relationship between SES (ABEP scale), age and cognitive/neuropsychological performance of the children structural equation modeling was conducted, using Mplus software version 6.0 (Muthén and Muthén 2007). First, the construction of measurement models will be described, and finally, the structural model. The indexes of adjustments of models are presented according to Byrne (2011). The measurement models were based on factor analysis of the instrument NEUPSILINInf, proposed by Salles et al. (2014), using maximum likelihood (ML) as an estimation method. The following tasks were used: rhyme, phonemic subtraction, reading words and pseudowords, spontaneous writing and reading comprehension as indicators of the latent variable oral and written language. The tasks digit span (forward and backward), pseudoword span and visuospatial working memory composed the latent variable working memory. The go-no go task and the orthographic and semantic verbal fluency tasks were used as indicators of the latent variable executive functions (inhibitory control component). The latent variable verbal memory was composed of the following tasks: semantic memory, episodic memory (immediate recall) and visuoverbal episodic memory. The measurement model showed satisfactory fit indices: $\chi^{2}(102)=178.63 \quad(p<0.01) ; \quad \chi^{2} / \mathrm{gl}=1.751$; Comparative Fit Index - CFI $=0.973$; Tucker-Lewis Fit Index - TLI = 0.964; Root Mean Square Error of Approximation - RMSEA $=0.042$ (Confidence Interval - CI $90 \%$ : 0.032-0.052); Standardized Root Mean Square Residual $\mathrm{SRMR}=0.037$.

The structural models included the SES variables and IQ and is represented in Fig. 1. Once the literature has affirmed that there are differences in the contribution of SES to the different ages, we made the structural models by age range $(6-7,8-9,10-12)$. In general, the structural models showed satisfactory fit indices, according to Table 2. Although $\chi^{2}$ has $p<0.01$, according to Byrne (2011) this measurement has been considered very sensitive to the sampling size, and $\mathrm{p}$ values like those obtained in this paper have been accepted (Byrne 2011), without compromising good model fit. The estimated coefficients are reported in Fig. 1 (STDYX standardization method). There was a statistically significant difference between the contributions of SES to the performance on the tasks assessed between the age groups, as follows: six/seven years and eight/nine years $\left(\chi^{2}(10)=27.9\right.$, $\left.\chi^{2} / \mathrm{gl}=2.79 ; \quad p<0.05\right)$, between six/seven and ten/ eleven/twelve years $\left(\chi^{2}(10)=115.475, \chi^{2} / \mathrm{gl}=11.547 ; p\right.$ $<0.05)$ and between eight/nine and ten/eleven/twelve years $\left(\chi^{2}(10)=87.57, \chi^{2} / \mathrm{gl}=8.757 ; p<0.05\right)$.

The structural model for maternal and paternal education as predictors showed satisfactory indices, according to Table 2 (models by age range). There was a statistically significant difference between the contributions of maternal education to the performance in the assessed tasks between the following age groups: six/seven years and eight/ nine years $\left(\chi^{2}(10)=4.529, \chi^{2} / \mathrm{gl}=0.453 ; p<0.05\right)$, six/seven and ten/eleven/twelve years $\left(\chi^{2}(10)=116.853, \chi^{2} / \mathrm{gl}=11.68\right.$; $p<0.05)$ and between eight/nine and ten/eleven/twelve years $\left(\chi^{2}(10)=70.323, \chi^{2} / \mathrm{gl}=7.032 ; p<0.05\right)$. Likewise, regarding parental education, the values obtained for paternal education were: between six/seven years and eight/nine years $\left(\chi^{2}(10)=44.298, \chi^{2} / \mathrm{gl}=4.43 ; p<0.05\right)$, between six/seven and ten/eleven/twelve years $\left(\chi^{2}(10)=104.134, \chi^{2} /\right.$ $\mathrm{gl}=10.413 ; p<0.05)$ and between eight/nine and ten/ eleven/twelve years $\left(\chi^{2}(10)=59.836, \chi^{2} / \mathrm{gl}=5.984 ; p<0.05\right)$ (see Figs. 2 and 3). The estimated coefficients are reported in Figs. 2 and 3 (STDYX standardization method).

\section{Discussion}

The results show a moderate effect of SES and specifically parental education (mainly maternal education) on the performance in memory (working memory), language and executive functions, especially for younger children (from 6 to 12 years old). The children with lower SES had lower performance regarding IQ, verbal episodic and semantic memory, working memory, written language, visuoverbal memory and inhibitory control tasks than those with higher SES. The findings of the present study are consistent with those from other studies that have demonstrated the contribution of SES to cognitive performance at different age ranges, especially in younger children (Blair et al. 2011; Lupien et al. 2001; Noble et al. 2006, 2007; Piccolo et al. 2012). In fact, the magnitude of the relationship between SES and the identified factors were similar to other studies conducted in other contexts, like US and Canada (Lupien et al. 2001; Noble et al. 2006, 2007).

In the early years of childhood until school age, the socioeconomic status is a major factor since it may limit the conditions of the environment, what impacts on stimulation, access to materials and activities that favor cognitive development, presence of parents or caregivers and willingness to engage in activities with the child (Forns et al. 2012). Cognition, in general, and more specifically, memory, language and executive functions, seem to be more affected by the socioeconomic environment, due to its 
Table 1 Participants' Performances (Mean and Standard Deviation) in IQ and Language, Memory and Executive Functions by Socioeconomic Status and Age Range

\begin{tabular}{|c|c|c|c|c|c|c|c|c|c|c|c|c|c|}
\hline \multirow{3}{*}{$\begin{array}{l}\text { Tasks } \\
\text { SES } \\
\text { Age range }\end{array}$} & & \multicolumn{12}{|c|}{ Groups } \\
\hline & & \multicolumn{3}{|l|}{$\bar{A}$} & \multicolumn{3}{|l|}{ B1 } & \multicolumn{3}{|l|}{ B2 } & \multicolumn{3}{|l|}{ C } \\
\hline & & $\overline{6-7}$ & $8-9$ & $10-12$ & $\overline{6-7}$ & $8-9$ & $\frac{10-12}{10}$ & $\overline{6-7}$ & $8-9$ & $10-12$ & $6-7$ & $8-9$ & $\overline{10-12}$ \\
\hline \multirow[t]{2}{*}{$\mathrm{IQ}$} & $M$ & 25.52 & 31.74 & 32.16 & 25.14 & 29.24 & 31.41 & 24.29 & 27.97 & 30.70 & 20.76 & 26.52 & 30.52 \\
\hline & $S D$ & 4.69 & 2.66 & 3.05 & 4.71 & 5.37 & 3.36 & 3.97 & 4.46 & 3.64 & 5.07 & 4.72 & 3.57 \\
\hline \multicolumn{14}{|l|}{ Semantic and episodic memory } \\
\hline \multirow[t]{2}{*}{ Immediate recall } & M & 4.70 & 5.08 & 5.50 & 4.50 & 4.57 & 5.59 & 4.54 & 5.45 & 5.60 & 4.00 & 4.84 & 5.19 \\
\hline & SD & 1.36 & 1.24 & 1.08 & 1.25 & 1.21 & 1.06 & 1.07 & 1.23 & 1.25 & 1.05 & 0.80 & 0.95 \\
\hline \multirow[t]{2}{*}{ Late recall } & $M$ & 3.03 & 3.95 & 3.98 & 3.28 & 3.17 & 4.07 & 3.43 & 4.45 & 4.28 & 2.19 & 3.12 & 3.87 \\
\hline & $S D$ & 1.45 & 1.64 & 1.45 & 1.65 & 1.37 & 1.19 & 1.55 & 1.03 & 1.49 & 1.72 & 1.27 & 1.15 \\
\hline \multirow[t]{2}{*}{ Visuoverbal } & $M$ & 4.76 & 5.74 & 6.25 & 5.56 & 5.61 & 6.18 & 4.96 & 5.61 & 6.32 & 4.43 & 5.52 & 5.77 \\
\hline & $S D$ & 1.15 & 1.39 & 1.15 & 1.13 & 1.19 & 1.13 & 1.11 & 0.92 & 1.24 & 1.03 & 1.23 & 0.85 \\
\hline \multirow[t]{2}{*}{ Semantic } & $M$ & 3.73 & 3.90 & 3.94 & 3.67 & 3.74 & 3.98 & 3.32 & 3.94 & 3.98 & 3.33 & 3.80 & 3.87 \\
\hline & $S D$ & 0.45 & 0.38 & 0.24 & 0.48 & 0.54 & 0.15 & 0.48 & 0.25 & 0.15 & 0.73 & 0.41 & 0.34 \\
\hline \multicolumn{14}{|l|}{ Working memory } \\
\hline \multirow[t]{2}{*}{ Digit span (forward) } & $M$ & 17.27 & 20.69 & 22.15 & 17.50 & 18.74 & 21.48 & 16.96 & 18.68 & 21.04 & 13.62 & 16.92 & 19.45 \\
\hline & $S D$ & 4.29 & 3.79 & 2.44 & 3.37 & 4.08 & 2.76 & 3.24 & 3.90 & 3.04 & 3.71 & 4.87 & 3.55 \\
\hline \multirow[t]{2}{*}{ Digit span (backward) } & $M$ & 16.15 & 20.46 & 21.88 & 16.06 & 19.04 & 20.45 & 15.29 & 18.32 & 20.17 & 10.67 & 17.60 & 20.84 \\
\hline & $S D$ & 5.14 & 4.51 & 3.85 & 4.61 & 3.86 & 3.68 & 5.40 & 4.20 & 3.73 & 5.21 & 4.42 & 3.49 \\
\hline \multirow[t]{2}{*}{ Pseudoword span } & $M$ & 11.19 & 14.50 & 14.87 & 11.67 & 12.57 & 14.20 & 10.30 & 12.35 & 14.43 & 10.33 & 10.79 & 13.19 \\
\hline & $S D$ & 3.53 & 3.46 & 3.36 & 3.14 & 3.88 & 2.73 & 2.70 & 2.68 & 3.12 & 3.09 & 2.87 & 2.96 \\
\hline \multirow[t]{2}{*}{ Visuospatial working memory } & $M$ & 19.64 & 23.89 & 25.08 & 17.83 & 22.91 & 24.09 & 17.71 & 22.42 & 23.23 & 11.38 & 22.04 & 23.68 \\
\hline & SD & 6.01 & 5.63 & 3.17 & 7.21 & 4.90 & 3.99 & 5.56 & 5.28 & 3.78 & 7.05 & 6.00 & 4.26 \\
\hline \multicolumn{14}{|l|}{ Language } \\
\hline \multirow[t]{2}{*}{ Rhyme } & $M$ & 3.58 & 3.77 & 3.94 & 3.47 & 3.48 & 3.82 & 3.32 & 3.58 & 3.81 & 2.86 & 3.52 & 3.74 \\
\hline & $S D$ & 0.75 & 0.49 & 0.24 & 0.77 & 0.67 & 0.39 & 0.91 & 0.67 & 0.39 & 0.95 & 0.59 & 0.45 \\
\hline \multirow[t]{2}{*}{ Phonemic subtraction } & $M$ & 5.30 & 5.77 & 5.87 & 5.17 & 5.26 & 5.80 & 5.00 & 5.55 & 5.89 & 3.62 & 5.32 & 5.61 \\
\hline & $S D$ & 1.10 & 0.54 & 0.49 & 1.40 & 0.97 & 0.55 & 1.16 & 0.77 & 0.31 & 1.69 & 1.41 & 0.56 \\
\hline \multirow[t]{2}{*}{ Listening } & $M$ & 4.73 & 4.87 & 4.87 & 4.86 & 4.61 & 4.82 & 4.79 & 4.81 & 4.89 & 4.71 & 4.84 & 4.97 \\
\hline & $S D$ & 0.45 & 0.34 & 0.35 & 0.35 & 0.50 & 0.39 & 0.42 & 0.40 & 0.31 & 0.46 & 0.37 & 0.18 \\
\hline Inferential processing & $M$ & 2.39 & 5.23 & 6.96 & 2.58 & 5.39 & 6.59 & 2.39 & 4.94 & 6.15 & 1.24 & 4.08 & 6.29 \\
\hline & $S D$ & 2.29 & 1.95 & 1.12 & 2.35 & 1.97 & 1.37 & 2.57 & 1.95 & 1.30 & 1.67 & 2.48 & 1.79 \\
\hline Reading words and pseudowords & $M$ & 15.03 & 16.03 & 16.52 & 14.17 & 15.74 & 16.34 & 13.46 & 16.10 & 16.17 & 9.67 & 15.40 & 16.29 \\
\hline & $S D$ & 1.94 & 1.04 & 0.58 & 3.73 & 1.39 & 0.57 & 4.28 & 0.94 & 0.70 & 5.41 & 1.63 & 0.74 \\
\hline Reading comprehension & M & 4.82 & 4.97 & 4.90 & 4.56 & 4.96 & 4.98 & 4.75 & 4.94 & 4.98 & 3.76 & 4.88 & 4.94 \\
\hline & $S D$ & 0.53 & 0.16 & 0.69 & 1.11 & 0.21 & 0.15 & 0.59 & 0025 & 0.15 & 1.26 & 0.44 & 0.25 \\
\hline spelling & $M$ & 15.03 & 17.79 & 18.44 & 14.03 & 17.26 & 18.43 & 13.36 & 17.60 & 18.15 & 8.70 & 16.40 & 18.19 \\
\hline & $S D$ & 2.65 & 1.32 & 0.73 & 4.28 & 1.57 & 0.45 & 4.08 & 1.40 & 1.12 & 5.95 & 2.12 & 1.01 \\
\hline Spontaneous writing & $M$ & 1.33 & 1.90 & 1.96 & 1.25 & 1.78 & 1.84 & 1.11 & 1.84 & 1.81 & 0.67 & 1.24 & 1.84 \\
\hline & $S D$ & 0.65 & 0.31 & 0.19 & 0.84 & 0.42 & 0.37 & 0.79 & 0.45 & 0.45 & 0.80 & 0.52 & 0.37 \\
\hline Written copy of words & $M$ & 1.70 & 1.92 & 1.98 & 1.75 & 1.96 & 1,91 & 1.61 & 1.81 & 2.00 & 1.71 & 1.76 & 1.97 \\
\hline & $S D$ & 0.47 & 0.27 & 0.14 & 0.50 & 0.21 & 0,29 & 0.57 & 0.48 & 0 & 0.46 & 0.44 & 0.18 \\
\hline
\end{tabular}


Table 1 Participants' Performances (Mean and Standard Deviation) in IQ and Language, Memory and Executive Functions by Socioeconomic Status and Age Range (Continued)

\begin{tabular}{lcrrrrrrrrrrrr}
\hline Executive Functions & & & & & & & & & & & \\
Orthographic verbal fluency & $M$ & 5.58 & 8.03 & 10.02 & 6.11 & 7.78 & 9.70 & 5.86 & 7.84 & 9.89 & 4.40 & 7.87 & 8.52 \\
& SD & 2.37 & 3.44 & 3.32 & 3.05 & 3.83 & 2.90 & 2.88 & 2.91 & 4.27 & 2.11 & 3.04 & 3.72 \\
Semantic verbal fluency & $M$ & 11.82 & 14.77 & 18.46 & 12.56 & 15.39 & 15.95 & 11.36 & 13.19 & 16.96 & 10.00 & 12.44 & 15.74 \\
& SD & 3.69 & 3.38 & 3.94 & 3.86 & 5.05 & 5.26 & 4.67 & 3.89 & 5.11 & 4.10 & 3.71 & 4.67 \\
go-no go task & $M$ & 51.42 & 55.03 & 57.13 & 50.17 & 55.96 & 57.89 & 49.68 & 55.94 & 57.09 & 45.70 & 52.04 & 56.90 \\
& SD & 6.36 & 3.54 & 4.82 & 7.76 & 4.65 & 2.89 & 6.35 & 3.72 & 3.27 & 6.91 & 6.96 & 3.66 \\
\hline
\end{tabular}

Obs. $M$ Mean, $S D$ standard deviation

prolonged development - at a neuroanatomical level -, which may lead to increased susceptibility to environmental differences (Noble et al. 2006). Besides, SES is strongly related to other environmental aspects such as maternal depression and the amount of time spent by parents in activities with their children (Piccolo et al. 2012).

Our results showed that SES effects on cognition decline after nine years old. Lupien et al. (2001) found a similar result and justify that the SES differences could be due to the school environments and also to the neighborhood environments in which children are exposed as a function of SES. In this case, the neuropsychological performance would be influenced by social interactions with peers and teachers at school. In this perspective, the school system - that supposedly give the same resources for all students - and living in other spaces with another people, associated to children character (as resilience), could equalize the performance of children from different socioeconomic contexts. Another hypothesis refers to psychological characteristic of "shift-and-persist" (Chen et al. 2012), consisting of reframing appraisals of current stressors more positively (shifting), while simultaneously persisting with a focus on the future. This characteristic would be associated with reduced physiological risk in low childhood SES individuals, helping them to deal with risks environments (Chen et al. 2012).

In the present study, both the SES and specifically parental education showed independent effects, on IQ. The greatest effects were observed in younger children (up to nine years old). Studies of twins and adopted children provide evidence that genetic and environmental factors impact on general intelligence ( $g$ factor) and that a substantial part of the variation of cognitive ability in adulthood is explained by genetic variations (Blair 2006). Specifically, the heritability estimates the factor $\mathrm{g}$ in young children are about $20 \%$ and decreases as a function of SES (Turkheimer et al. 2003), supposing genotypic and phenotypical contributions to cognition. A model proposed by Eaves et al. (1986) explains development as a longitudinal process that incorporates new genetic and environmental effects on the phenotype and that changes may be specific to occasions or constant over time. The continuity of cognitive performance over time and the increase in heritability with age reflect the cumulative long-term effects of a single set of genes expressed throughout development. The quality of the shared

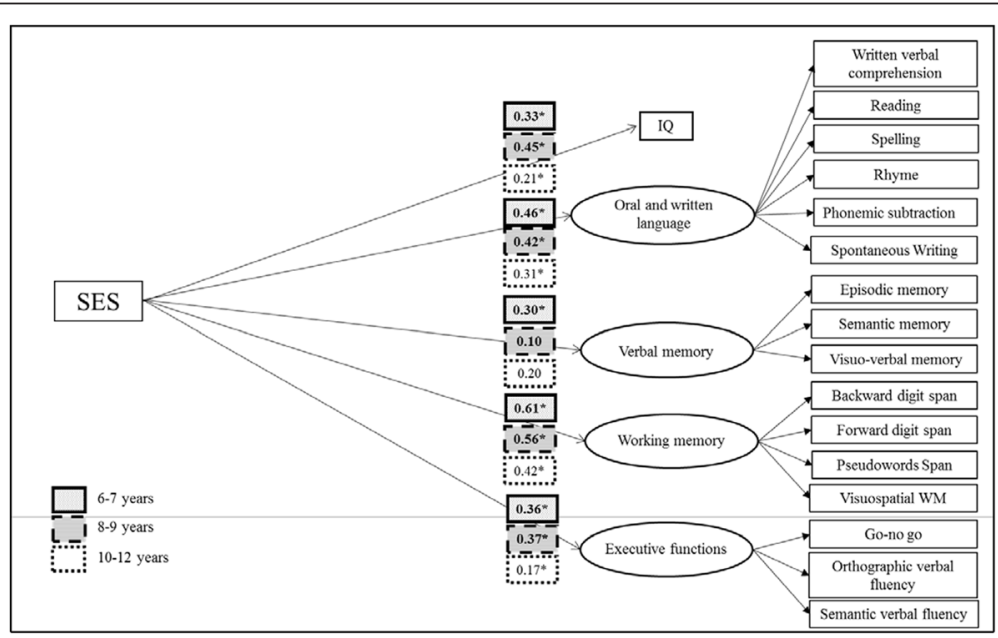

Fig. 1 Structural model (SES as a predictor) for six/seven, eight/nine and ten/eleven/twelve years old. ${ }^{*}=p<0.05$ 
Table 2 Indices for Adjustment of Structural Models

\begin{tabular}{lllllllll}
\hline Models & $X^{2}(g)$ & $p$ & $x^{2} / g l$ & CFI & TLI & RMSEA & IC 90 \% & SRMR \\
\hline VI: SES & $193.2(114)$ & 0.01 & 1.70 & $0.972 ;$ & 0.963 & 0.041 & $0.031-0.051$ & 0.036 \\
VI: maternal education & $204.4(114)$ & 0.01 & 1.79 & 0.968 & 0.957 & 0.044 & $0.034-0.054$ & 0.036 \\
Vl: paternal education & $196.6(114)$ & 0.01 & 1.72 & 0.970 & 0.960 & 0.043 & $0.032-0.052$ & 0.038 \\
\hline
\end{tabular}

Obs.VI independent variable (predictor)

environment changes from family to family over time appears to exercise a long-term effect on cognitive development (Eaves et al. 1986).

It can be seen that SES and parental education (especially maternal education) had a moderate, but significant effect on children's performance in written and oral language, as previously demonstrated by other studies (Noble et al. 2006, 2007). The acquisition of written language continuously improved with new skills, as the individual grows and it is totally dependent of the interactions with the environment (Finkbeiner and Coltheart 2009) that provides stimuli and experiences that are essential for this development as a primary means of social interaction (Kim 2009; Peeters et al. 2009). Low SES children are more likely to reside in an environment that exhibits sharply lower attainment levels and, in addition, that repeatedly manifests higher rates of crime, divorce, unemployment, and population density than high SES children. On the other hand, parents with high educational level tend to have substantially better educated spouses and higher family income. Also, they are more likely to invest in their children through books, providing special lessons, or availability of a computer, for example (Carneiro et al. 2013). That exposure to written material is essential for language development (Marturano 2006) and there is evidence that children whose parents read to them when they are very young are more prepared for the development of reading when they enter school due to their early contact with books (Duursma et al. 2008; Kuo et al. 2004). The lower the family SES, less frequent is the practice of literacy (Breit-Smith et al. 2010; Grieshaber et al. 2012).

Moreover, some aspects of phonological awareness, one of the best predictors of proficient reading (Foy and Mann 2003), depend on exposure to reading and home literacy (Kim 2009; Foy and Mann 2003), which also affects word recognition (Peeters et al. 2009). Mothers with higher educational level seem to be more likely to read frequently to their children than mothers with lower levels of education (Kuo et al. 2004; Skibbe et al. 2008), which may impact the development of written language in children.

It was showed that SES has an effect on memory. Dynamic models of multiple components, such as the sociocultural theory (Nelson and Fivush 2004), explains that memory development occurs through social interaction and cognitive development over the years. In the present study, children from socioeconomically disadvantaged households had poorer performance than those with high SES, especially until nine years old. According to Gathercole (1998), the basic structure of the working memory is formed at the age of six years, but the capacity of each component increases until adolescence. The main change that occurs during the development of working memory is the increase in the operational efficiency and speed of information processing, as well as greater use of

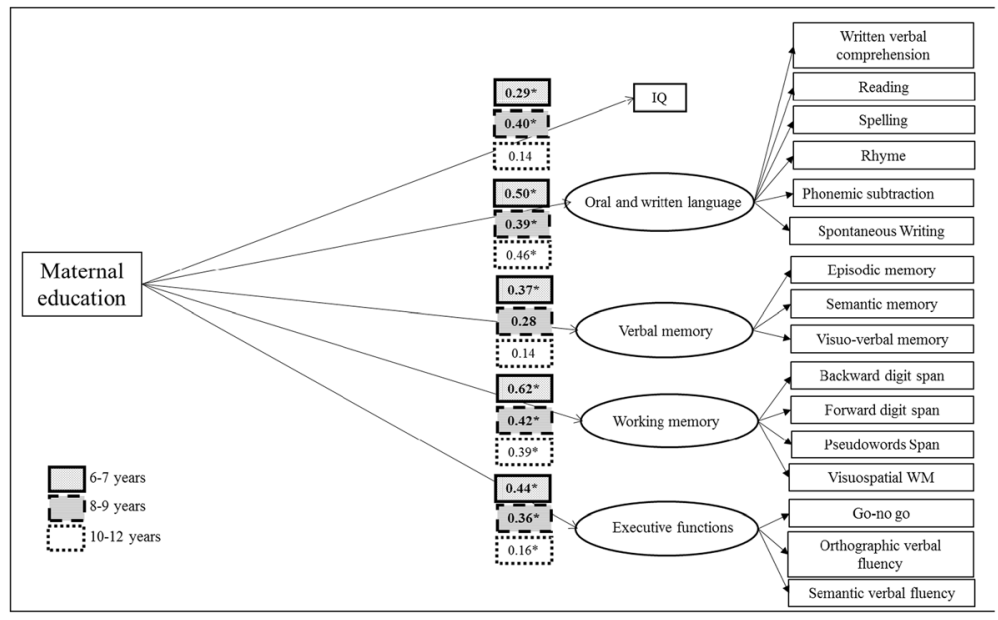

Fig. 2 Structural models (Maternal edducation as a predictor) for six/seven, eight/nine and ten/eleven/twelve years old. ${ }^{*}=p<0.05$ 


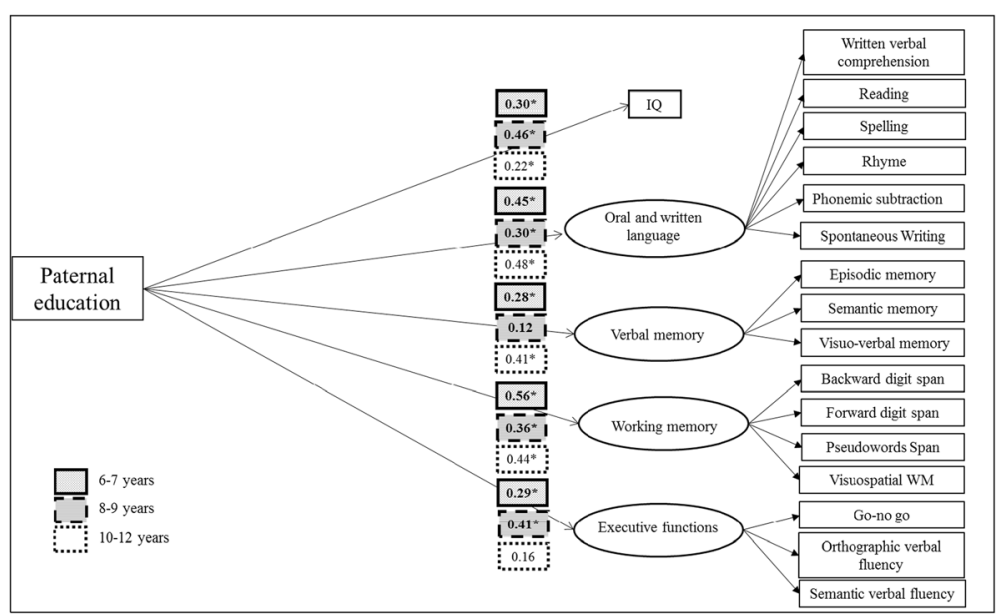

Fig. 3 Structural model (Paternal education as a predictor) for six/seven, eight/nine and ten/eleven/twelve years old. ${ }^{*}=p<0.05$

strategies in problem solving, skills that are influenced by the experiences of children in the family environment (Diamond and Lee 2011; Gathercole and Baddeley 1993).

Regarding the visuospatial component of the working memory, in those cases where visuospatial processing is very complex, the central executive component is triggered to assist in solving the task (Gathercole and Baddeley 1993). In turn, these skills are influenced by the experiences of children in the family environment - opportunities to perform tasks and demands of the environment that require the use of strategies to memorize information, for example - at school, and, thus, from the SES (Nelson and Fivush 2004).

In the present study, a significant contribution of the SES and parental education (especially maternal) to the latent variable executive functions was detected. The inhibitory control (assessed by go-no go tasks for example) occurs late in childhood. At 10 years of age, the ability to inhibit attention to irrelevant stimuli and motor responses is fairly complete, being usually mastered at the age of 12 (Romine and Reynolds 2005). In agreement with this assumption, in this study, it was found that only between 10 and 12 years, the difference in the go- no go task regarding SES was significant, and low SES children performing poorer in this task compared to those from higher SES. Models that include environmental, biological and cognitive factors try to explain the development of executive functions (Blair and Ursache 2011; Stuss 1992). They integrate the results of empirical research on the physiology of stress, neurocognitive functions and selfregulation and consider the adaptive processes response to adversity of the environment as an aspect of development of the child (Blair and Raver 2012). For example, Stuss (1992) propose a model with three hierarchical levels of processing: sensory-perceptual, executive control and self-reflexivity (metacognition), that interacting with the external environment and are mediated by the frontal lobes. The levels are interrelated and depend on the maturity of primary to higher processes functioning. Also, they are related to the demands of external and internal environment, seeking to maintain the body's adaptation in different situations. So, living in an adverse environment could impair the development of primaries levels and it would impact in the development of superior levels (Stuss 1992).

It is concluded that SES impact decreases with age, in general, except for those functions that develop at a later moment, in this case, inhibitory control. Our study measures were similar to those that have been used in other countries studies that compared SES and performance in neuropsychological tasks. Once we have achieved results similar to those found in "first world countries", it seems that the impact of SES occurs independently of the culture studied, although the developed countries poverty rates are different from developing countries, poverty both there and here is damaging for cognitive development.

Limitations of this study include the use of a short battery that does not have many tasks to widely evaluate neuropsychological functions. Especially in the case of executive functions, few components were evaluated by the three tasks used. On the other hand, the tasks used are from an instrument made for the Brazilian child population, with standards and evidence of validity and reliability for this sample. Another limitation could be that the sample are mostly from medium or high SES and even the poorer participants do not reflect the low SES we can see in some Brazilian regions.

\section{Conclusion}

In sum, findings from this study indicated that outcomes in language, memory and executive functions vary by SES and that these environment effects may manifest at 
particular developmental stages. The study has implications for interventions, such as associating cognitive stimulation strategies to compensate for the children's learning problems and their reduced neurocognitive development impacted by a lower SES, for example by increasing the frequency of reading and writing habits, and literacy practices, in addition to training teachers. Concerning public policies, it seems that investment in child development should start very early in life, according to this study. The investigators should consider the differences in SES in the formulation of their studies on the cognitive development. Besides, SES should be considered in the divisions of normative groups of neuropsychological tests. This study has no intention of providing a deterministic view on the effects of SES on the lives of the children and their families. Studies on this area are aimed to determine the variables that impact the development of brain and its functions and obtain tools to promote actions that revert and, ideally, prevent difficulties in children's neurocognitive development.

\section{Competing interests}

The authors declare that they have no competing interests.

\section{Authors' contributions}

LRP conceived of the study, analyzed the data and participated in its design and wrote the manuscript. AXA helped to analyze the data, participated in the design of the study and helped to write the manuscript RPF participated in the study design and coordination and helped to write the manuscript RGO conceived of the study, and participated in its design and coordination and helped to write the manuscript. JFS conceived of the study, and participated in its design and coordination and helped to write the manuscript. All authors read and approved the final manuscript.

\section{Acknowledgements}

This research was supported by the Brazilian National Council for the Improvement of Higher Education (CAPES).

Received: 15 March 2016 Accepted: 7 April 2016

Published online: 19 April 2016

\section{References}

Angelini, A. L., Alves, I. C. B., Custódio, E. M., Duarte, W. F., \& Duarte, J. L. M. (1999). Matrizes progressivas coloridas de Raven: escala especial [Manual]. São Paulo: Centro Editor de Testes e Pesquisas em Psicologia.

Arán-Filippetti V. Funciones ejecutivas en niños escolarizados: efectos de la edad y del estrato socioeconómico. Avances en psicología latinoamericana. 2011;29(1):98-113.

Ardila A, Rosselli M, Matute E, Guajardo S. The influence of the parents' educational level on the development of executive functions. Dev Neuropsychol. 2005:28(1):539-60

Associação Brasileira de Empresas de Pesquisa (2009). Critério de Classificação Econômica Brasil. Recuperado em 30 setembro, 2013, de http://www.abep.org/

Baddeley AD. The episodic buffer: a new component of working memory? Trends Cognit Sci. 2000;4:417-23.

Banich MT. Executive function: The search for a integrated account. Curr Direct Psychol Sci. 2009;18:89-94

Blair C. Toward a revised theory of general intelligence: Further examination of fluid cognitive abilities as unique aspects of human cognition. Behav Brain Sci. 2006:29:145-60.

Blair C, Raver CC. Child Development in the Context of Adversity: Experiential Canalization of Brain and Behavior. Am Psychol. 2012. doi:10.1037/a0027493. Advance online publication.
Blair C, Ursache A. A bidirectional model of executive functions and selfregulation. In: Vohs KD, Baumeister RF, editors. Handbook of self-regulation: Research, theory, and applications. New York: Guilford; 2011.

Blair C, Zelazo PD, Greenberg M. The assessment of executive function in early childhood: Prospects and progress. Dev Neuropsychol. 2005;28:561-71.

Blair C, Granger DA, Willoughby M, Mills-Koonce R, Cox M, Greenberg MT, FLP Investigators. Salivary cortisol mediates effects of poverty and parenting on executive functions in early childhood. Child Dev. 2011;82(6):1970-84.

Braveman PA, Cubbin C, Egerter S, Chideva S, Marchi KS, Metzler M, Posner S. Socioeconomic status in health research: one size does not fit all. JAMA. 2005:294:2879-88.

Breit-Smith A, Cabell SQ, Justice LM. Home Literacy Experiences and Early Childhood Disability: A Descriptive Study Using the National Household Education Surveys (NHES) Program Database. Lang Speech Hear Serv Sch. 2010;41(1):96-107.

Brito GN. The Conners Abbreviated Teacher Rating Scale: development of norms in Brazil. J Abnorm Child Psychol. 1987;15(4):511-8.

Brocki KC, Bohlin G. Executive functions in children aged 6 to 13: A dimensional and developmental study. Developmental Neuropsychology. 2004;26:571-593.

Byrne BM. Structural equation modeling with Mplus : basic concepts, applications, and programming. London: Routledge Academic; 2011

Carneiro P, Meghir C, Parey M. Maternal education, home environments and the development of children and adolescents. J Eur Econ Assoc. 2013;11(1):123-60.

Cesare MD, Sabate R, Lewin KM. A double prevention: how maternal education can affect maternal mental health, child health and child cognitive development. Longitudinal Life Course Stud. 2013;4(3):166-79.

Chen E, Miller G, Lachman ME, Gruenewald TL, Seeman TE. Protective Factors for Adults from Low Childhood Socioeconomic circumstances: The Benefits of Shift-and- Persist for Allostatic Load. Psych Med. 2012;74(2):178-86.

Cuadro, J. A., \& Balbi, A. (2012). Las diferencias socioeconómicas y la lectura: claves para analizar los resultados de las evaluaciones PISA. Neuropsicologia Latinoamericana, 4(1). Recuperado de http://neuropsicolatina.org/index.php/ Neuropsicologia_Latinoamericana/article/view/93

de Salles JF, Fonseca RP, Cruz-Rodrigues C, Mello CB, Barbosa T, Miranda MC. Development of the Child Brief Neuropsychological Assessment Battery NEUPSILIN-INF. Psico-USF. 2011;16(3):297-305.

Diamond A. Executive Functions. Annu Rev Psychol. 2013:64:135-68.

Diamond A, Lee K. Interventions Shown to Aid Executive Function Development in Children 4 to 12 Years Old. Science. 2011:333(6045):959-64.

Duursma E, Pan BA, Raikes H. Predictors and outcomes of low-income fathers reading with their toddlers. Early Childhood Res Quart. 2008;23:351-65.

Eaves $L$, Long J, Heath AC. A theory of developmental change in quantitative phenotypes applied to cognitive development. Behav Genet. 1986;16(1):143-62.

Engel PMJ, Santos FH, Gathercole SE. Are working memory measures free of socioeconomic influence? J Speech Lang Hear Res. 2008;51(6):1580-7.

Evans GW, Fuller-Rowell TE. Childhood poverty, chronic stress, and young adult working memory: the protective role of self-regulatory capacity. Dev Sci. 2013:16(5):688-96. doi:10.1111/desc.12082.

Finkbeiner M, Coltheart M. Letter recognition: from perception to representation. Introduction. Cogn Neuropsychol. 2009;26(1):1-6.

Forns J, Julvez J, García-Esteban R, Guxens M, Ferrer M, Grellier J, Sunyer J. Maternal intelligence-mental health and child neuropsychological development at age 14 months. Gaceta Sanitaria / S.E.S.P.A.S. 2012;26(5):397404. doi:doi: 10.1016/j.gaceta.2011.10.011.

Foy JG, Mann V. Home literacy environment and phonological awareness in preschool children: Differential effects for rhyme and phoneme awareness. Appl Psycholinguist. 2003;24:59-88.

Fuster JM. Frontal lobe and cognitive development. J Neurocytol. 2002;31(3-5):373-85.

Gathercole SE, Baddeley AD. Working Memory and Language. Hove, UK: Psychology Press; 1993.

Grieshaber S, Shield P, Luke A, Macdonald S. Family literacy practices and home literacy resources: An Australian pilot study. J Early Childhood Literacy. 2012; 12(2):113-38.

Haan MN, Zeki Al-Hazzouri A, Aiello AE. Life-span Socioeconomic Trajectory, Nativity, and Cognitive Aging in Mexican Americans: The Sacramento Area Latino Study on Aging. J Gerontol B Psychol Sci Soc Sci. 2011;66B(Supplement 1):i102-10.

Hackman DA, Farah MJ, Meaney MJ. Socioeconomic status and the brain: mechanistic insights from human and animal research. Nature Reviews. Neuroscience. 2010:11(9):651-9.

Instituto Brasileiro de Geografia e Estatistica - IBGE. (2012). Projeção da população do Brasil por sexo e idade: 1980-2050. Revisão 2012. Estudos e Pesquisas DPE, IBGE, n. 24. 
Kim YS. The relationship between home literacy practices and developmental trajectories of emergent literacy and conventional literacy skills for Korean children. Read Writ. 2009;22(1):57-84.

Klenberg L, Korkman M, Lahti-Nuuttila P. Differential development of attention and executive functions in 3- to 12-year-old Finnish children. Dev Neuropsychol. 2001;20(1):407-28.

Kuo AA, Franke TM, Regalado M, Halfon N. Parent report of reading to young children. Pediatrics. 2004;113(6 Suppl):1944-51.

Lipina JL, Segretin MS. Strengths and weakness of neuroscientific investigations of childhood poverty: future directions. Front Hum Neurosci. 2015:9(53):1-11.

Lipina S, Segretin S, Hermida J, Prats L, Fracchia C, Camelo JL, Colombo J. Linking childhood poverty and cognition: environmental mediators of non-verbal executive control in an Argentine sample. Dev Sci. 2013;16(5):697-707.

Lúcio PS, Pinheiro AMV, Nascimento E. A Influência de fatores sociais, individuais e linguísticos no desempenho de crianças na leitura em voz alta de palavras isoladas. Psicologia. 2010;23(3):496-505.

Lupien SJ, King S, Meaney MJ, McEwen BS. Can poverty get under your skin? basal cortisol levels and cognitive function in children from low and high socioeconomic status. Dev Psychopathol. 2001;13(3):653-76.

Marturano EM. The home environment resources scale. Psicologia. 2006;19(3): 498-506.

Miranda ML, Kim D, Galeano MAO, Paul CJ, Hull AP, Morgan SP. The relationship between early childhood blood lead levels and performance on end-ofgrade tests. Environ Health Perspect. 2007;115(8):1242-7.

Muthén LK, Muthén BO. Mplus User's Guide. 6th ed. Los Angeles: Muthén \& Muthén; 2007.

Nelson K, Fivush R. The emergence of autobiographical memory: a social cultural developmental theory. Psychol Rev. 2004;111(2):486-511.

Noble KG, Farah MJ. Neurocognitive consequences of socioeconomic disparities: the intersection of cognitive neuroscience and public health. Dev Sci. 2013; 16(5):639-40. doi:10.1111/desc.12076.

Noble KG, Wolmetz ME, Ochs LG, Farah MJ, McCandliss BD. Brain-behavior relationships in reading acquisition are modulated by socioeconomic factors. Dev Sci. 2006;9(6):642-54

Noble KG, McCandliss BD, Farah MJ. Socioeconomic gradients predict individual differences in neurocognitive abilities. Dev Sci. 2007:10(4):464-80.

Noble KG, Houston SM, Bartsch H, Kan E, Kuperman JM, Akshoomoff N, Amaral DG, Sowell ER. Family income, parental education and brain development in children and adolescents. Nat Neurosci. 2015;18(5):773-8.

Peeters M, Verhoeven L, de Moor J, van Balkom H, van Leeuwe J. Home literacy predictors of early reading development in children with cerebral palsy. Res Dev Disabil. 2009;30(3):445-61.

Piccolo LR, Falceto OG, Fernandes CL, Levandowski DC, Grassi-Oliveira R, Salles JF. Psychosocial variables and reading performance of children with low socioeconomic status. Psicologia. 2012;28(4):389-98.

Piccolo LR, Sbicigo JS, Grassi-Oliveira R, Salles JF. Do SES and stress reactivity impact neurocognitive performance? Psychol Neuroscie. 2014;7(4):567-75.

Raizada RDS, Kishiyama MM. Effects of socioeconomic status on brain development, and how cognitive neuroscience may contribute to levelling the playing field. Front Hum Neurosci. 2010;4(3):1-11.

Romine CB, Reynolds CR. A model of the development of frontal lobe functioning: findings from a meta-analysis. Appl Neuropsychol. 2005;12(4): 190-201.

Salles JF, Sbicigo JB, Machado WL, Miranda MC, Fonseca RP. Análise Fatorial Confirmatória do Instrumento de Avaliação Neuropsicológica Breve Infantil NEUPSILIN - Inf. Psico-USF. 2014;19(1):119-30.

Salles JF, Fonseca RP, Parente MAMP, Miranda MC, Rodrigues CC, Mello CB, Barbosa T. Instrumento de Avaliação Neuropsicológica Breve Infantil NEUPSILIN-INF. São Paulo: Vetor; in press

Skibbe LE, Justice LM, Zucker TA, McGinty AS. Relations Among Maternal Literacy Beliefs, Home Literacy Practices, and the Emergent Literacy Skills of Preschoolers With Specific Language Impairment. Early Educ Dev. 2008;19(1):68-88.

Stuss DT. Biological and psychological development of executive functions. Brain Cogn. 1992;20(1):8-23.

Tomalski P, Moore DG, Ribeiro H, Axelsson EL, Murphy E, Karmiloff-Smith A, Kushnerenko E. Socioeconomic status and functional brain development associations in early infancy. Dev Sci. 2013;16(5):676-87.

Turkheimer E, Haley A, Waldron M, D'Onofrio B, Gottesman II. Socioeconomic status modifies heritability of IQ in young children. Psychol Sci. 2003;14(6):623-8.

Villaseñor EM, Sanz Martín A, Gumá Díaz E, Ardila A, Rosselli M, Ardila A. Influencia del nivel educativo de los padres, el tipo de escuela y el sexo en el desarrollo de la atención y la memoria. Revista latinoamericana de psicologia. 2009;41(2):257-76.

Waber DP, De Moor C, Forbes PW, Almli CR, Botteron KN, Leonard G, Rumsey J. The NIH MRI study of normal brain development: performance of a population based sample of healthy children aged 6 to 18 years on a neuropsychological battery. J Int Neuropsychol Soc. 2007;13(5):729-46.

Weyandt LL. Executive function in children, adolescents, and adults with attention deficit hyperactivity disorder: introduction to the special issue. Dev Neuropsychol. 2005;27(1):1-10.

Wiebe SA, Espy KA, Charak D. Using confirmatory factor analysis to understand executive control in preschool children: I. Latent structure. Dev Psychol. 2008; 44(2):575-87.

\section{Submit your manuscript to a SpringerOpen ${ }^{\circ}$ journal and benefit from:}

- Convenient online submission

- Rigorous peer review

- Immediate publication on acceptance

- Open access: articles freely available online

- High visibility within the field

- Retaining the copyright to your article

Submit your next manuscript at $>$ springeropen.com 